\title{
The Application of Translation Procedures in Translating Five Public Signs in Ubud
}

\author{
Ni Made Ariani \\ Faculty of Humanities, Udayana University, Bali, Indonesia \\ Ketut Artawa \\ Faculty of Humanities, Udayana University, Bali, Indonesia
}

\begin{abstract}
This study analyzes five public signs in English found in the area of Ubud, Bali, Indonesia. The purposes of this research are to identify the grammatical errors in the process of translating the information conveyed on these five public signs and to understand the translation procedures applied in the translation process. The first finding of this study is that grammatical errors are found on the first, second and fifth public signs. Meanwhile, the second finding of this study is four translation procedures are applied, which are Modulation, Transposition, Literal Translation and Calque. Another interesting finding, which can be found in this research, is the fact that the application of these translation procedures plays a very crucial role in determining the quality of the translation product as well as in contributing the occurrence of the grammatical errors.
\end{abstract}

Index Terms - translation procedures, grammatical errors, public signs

\section{INTRODUCTION}

Translation is the process of re-expressing the meaning derived from the Source Language (SL) into the Target Language (TL). The meaning re-expressed referred here must be the closest equivalence to the TL and the TL audiences. Anticipating a number of possibilities the TL audiences will perceive the re-expressed meaning plays one of the most significant considerations every translator will have to bear in mind. Strategies in conducting the translation process are studying the lexicon, grammatical structure, communication situation and cultural context of the SL text (Larson, 1998). These strategies show that the primary goal of the translation process is not merely transferring the form of the SL into the TL: in fact, it is the meaning transfer, which crucially determines the level of readability, acceptability and the accuracy of the translation product. Translating public signs then provides a number of challenges, especially when these translated signs are for audiences with varied languages and cultural backgrounds. As one of the most famous destinations in the world, the village of Ubud, Bali, Indonesia has been attracting large numbers of globetrotters. Public signs in Ubud are therefore not only serving the local community but also international visitors. From the goal of providing general information, suggestions, warnings, instructions on how things work, or even as marketing tools, public signs in Ubud are created for audiences from all over the world. The English translation of public signs in Ubud provides a vast opportunity for audiences to understand the intended meaning as well as the possibility to learn the linguistic features of Indonesian. The reflection of linguistic features of Indonesian can be observed through the errors occurring in the English translation of these public signs, which do not comply with English grammar. The common errors occurring in these public signs will not only be hard to understand but also potentially alter the intended meaning. Identifying the errors occurring and analyzing the translation procedures applied in translating these public signs into English are the goals of this research. These two goals show how intricate and complex the translation process can be. Public signs in general convey certain messages, which are commonly composed so concisely. The wordings tend to be short and precisely chosen. When this precision demands good quality or level of readability, acceptability and the accuracy of translation from one language to the other, then this can be regarded as a process to understand how powerful languages in general are and how unique the translating experience can be. Transferring the meaning from SL into TL, while at the same time understanding the linguistics as well as the cultural features of the TL are some of the crucial aspects that need to be considered in the translation process. Minimalizing the error occurrences of the translation product, while assuring this translation product can be read, understood and accepted are one of a number of challenges in translation studies.

\section{LiterATURE REVIEW \& THEORETICAL APPROACH}

Three articles about public sign translation are reviewed in order to understand the possible challenges encountered in the translation process along with the strategies applied in coping with these challenges. The first article (Aristova, 2016) examines dynamic changes in the linguistic landscape of Kazan, Russia, giving special attention to the introduction of English lexical elements and English translations from Russian and Tatar into the bilingual urban 
linguistic environment as a reflection of current globalization trends. The introduction of English into the linguistic landscape of Kazan and the mindsets of its people play a significant role in reflecting the transition from a strictly bilingual linguistic environment to a global multilingual one. The second article (Koskinen, 2012) studies the linguistic landscape of the suburb of Hervanta in Tampere, Finland from the perspective of translation studies. This study attempts to identify the translation consequences of the increasing multilingualism in Hervanta. The third article (Beili \& Tuo, 2015) investigates the Chinese-English translation (C-E) of linguistic signs from the perspective of linguistic landscape in the hope that people should notice the function of the organization that sets up the signs and their responsibility for the errors. In spite of possessing slightly different formulated problems, however, these three articles put a similar emphasis on acknowledging the cultural aspect involved in the translation process. Transferring a message from one language into another language requires a very deep understanding of both linguistics and culture. These two aspects will always be interwoven in each other's existence. It has been a shared-information concept that language transmits culture meanwhile culture regulates the language (Jiang, 2000). These two aspects are simply inseparable and contributing towards the entire process of meaning transfer and the quality of the translation product.

Two theories are applied in answering the two formulated problems of this research. The first theory (Halliday \& Matthiessen, 2014) is applied to identify the occurrence of the errors in these five selected public signs, specifically the grammatical construction as well as their spelling errors. The application of this theory is also expected to show whether Indonesian linguistic features can still be found in the English translation. Meanwhile, the second theory (Vinay \& Darbelnet, 2000) is applied to understand which translation procedures have been chosen by the translators in translating these five selected public signs. In addition, this theory is expected to show the possible factors causing the grammatical errors.

\section{A. Theory 1: Text \& Grammar}

Since the first formulated problem of this research is to identify the occurrence of errors in the English translated public signs, having a comprehensive understanding of English grammar in general is obligatorily required. This theory (Halliday \& Matthiessen, 2014) concerning functional grammar as well as the relationship between text and context is applied to assist in the process of identifying the occurrence of errors. Language is, in the first instance, a resource for making meaning; therefore, text is a process of making meaning in context (Halliday \& Matthiessen, 2014). This explanation is in line with the role of context and how it determines that the meaning from the SL transfers appropriately well into the TL. The precise nature of the public signs in terms of their wording arrangements reflects the importance of identifying the context of the public signs, which are to be translated in order to better help selecting the appropriate word choices and arrange them into compact and precise formation.

\section{B. Theory 2: Translation Procedures}

These are seven translation procedures (Vinay \& Darbelnet, 2000) utilized in this research. The first three procedures are categorized as Direct Translation; meanwhile the other four procedures are Oblique Translation. The idea of Direct Translation is to transpose the SL message element by element into the TL; while the nature of Oblique Translation is more complex concerning the adjustment process of the structural or metalinguistic differences between the SL and the TL. Procedure 1 - Borrowing: borrowing words or expressions from other languages, which are very unfamiliar or completely unknown in the TL. Procedure 2 - Calque: borrowing words or expressions from other languages, but these loans are then translated literally with respect to each of its elements. Procedure 3 - Literal Translation: the direct transfer of an SL text into a grammatically and idiomatically appropriate TL. Procedure 4 Transposition: replacing one word class or a grammatical category without changing the meaning of the message. Procedure 5 - Modulation: a variation of the form of the message, obtained by a change in the point of view. Procedure 6 - Equivalence: creating equivalences using completely different stylistic and structural methods. Procedure 7 Adaptation: creating a new situation that is considered as being equivalent in the TL as this type of situation referred in SL is unknown in the TL.

\section{METHOD}

Five public signs in Ubud are the data source of this research. These five public signs are chosen based on the uniqueness of their linguistic features and the location in Ubud whereabouts these signs are found. The exposure these five public signs obtained from visitors appears to be the main reason in selecting these public signs to be further analyzed. The creators of these public signs are local community officers, the management of the destinations and individuals. This research utilizes the qualitative descriptive approach to show the results of the studies in the field of translation in accordance with the discussion topics raised and the problems formulated in this study. Qualitative descriptive approach has the aim of describing, summarizing various forms of conditions, situations or phenomena in society which are the object of research (Bungin, 2007). A number of instruments were utilized in conducting this research, viz. the laptop, camera, items of stationery and two dictionaries (Indonesian - English and English Indonesian).

The data from these five public signs are taken by photograph and then transcribed by writing down the wordings conveyed by each of the signs. Among these five public signs, three of them are monolingual signs in English, while the 
other two are bilingual ones. The consideration in combining these two types of public signs is the fact that these all five public signs are able to provide linguistic phenomena to be further analyzed. For example, in spite of these three monolingual signs being in English and having no Indonesian version written on them, the reflection of Indonesian linguistic features can obviously be observed. Analyzing how this reflection may contribute to or interfere with the quality of the translation appears to be one of the reasons in utilizing the monolingual version of public signs. These collected data are analyzed to determine whether each public sign has errors in terms of its grammatical construction. Analysis is then conducted to determine the translation procedures applied in translating all of these five public signs into English. The final analysis is conducted to understand whether there is a possibility that the errors occur as the result of the application of these translation procedures. The analysis is presented by applying the formal and informal methods. The presentation of the results of the analysis is formally carried out by using tables, graphs, diagrams, signs and symbols, while the informal presentation of the results is carried out by using explanations through words or a number of informative sentences, which are to explain the results of the analysis (Sudaryanto, 1993). The explanation provided will make it easier for readers to understand formal media in the form of the tables and signs presented in this research. Two tables are presented to show the summary of the number of errors occur as well as the translation procedures applied.

\section{RESUlTS \& DisCUSSIONS}

The first public sign is found at The Sacred Monkey Forest Sanctuary Ubud. This sign is placed next to the reception area informing the visitors that this place is a non-smoking area. There is a grammatical error found in this first public sign. 'Kawasan bebas asap rokok' is translated into 'No Smoking' followed by the word 'area.' This is identified as an error since the adequate translation should have been 'A Non-Smoking Area.' The English translation can be read and understood but it does not comply with English grammar.

4.1.1 SL: Kawasan Bebas Asap Rokok

$$
\text { TL: "NO SMOKING" Area. }
$$

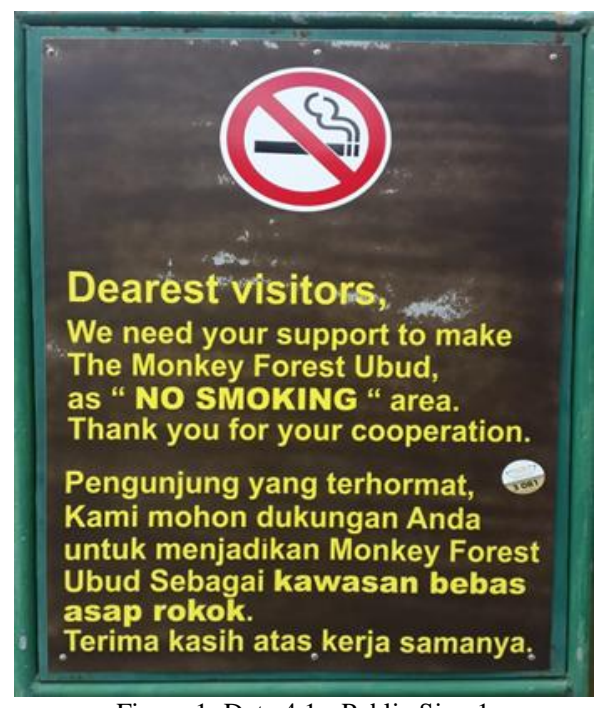

Figure 1: Data 4.1 - Public Sign 1

The core noun in this phrase is 'area.' Grammatically speaking, the phrase 'No Smoking area' is incorrect even though it already has a modifier. The correct one is 'A Non-Smoking Area.' Determiner 'A' followed by modifier 'Non-Smoking' precedes the core noun 'area.' Therefore, it can be said that an error occurs in translating this part on the first public sign. Another finding conveyed in this data 4.1 is observed in terms of its translation procedure. The word 'Bebas' is simply translated into 'No' instead of using its literal translation of 'Free.' Meanwhile, the noun phrase 'Asap rokok,' which literally means 'Cigarette smoke' is translated into 'Smoking.' These two translation processes significantly show that there are changes in grammatical structure. Therefore, in translating this part, it appears that the translator applies the procedure of Transposition. The adjective 'Bebas' is transposed into a verb and the noun phrase 'Asap rokok' is also transposed into a verb, yet these actions still adequately manage the entire meaning, conveying the idea that no one is allowed to smoke in this area. Apart from this grammatical error, it can be said that the English translation feels quite natural. This naturalness can be identified from its word choices. The natural word choices can also be observed through the translation of these three words, 'terhormat,' 'mohon' and suffix -nya in the word, 'samanya.' Below are three sentences containing these three words mentioned above.

\subsubsection{SL: Pengunjung Yang Terhormat}

TL: Dearest Visitors, 
The translator does not literally translate the word 'terhormat.' Instead of using the literal translation for the word 'terhormat,' which is 'respectable' and/or? 'honorable' among many other options in English, the translator opts for the word 'dearest.' The logical reason behind this decision might be based on the perspective this destination has in viewing or positioning its visitors. As one of the most famous destinations in Ubud or even Bali, The Sacred Monkey Forest Sanctuary Ubud has attracted visitors of all ages. 'All ages' serves as the key that determine the translator's decision in using the word 'dearest.' The target audiences of this public sign are 'all ages.' The word 'dearest' can be accepted by audiences of all ages. On the other hand, not all the visitors might feel comfortable being addressed as 'respectable' and 'honorable.' In fact, these two words might cause confusion and sound 'too much.' It might be safe to say that most tourists visit this destination for leisure pursuits. The warmth, togetherness, friendliness and informal atmospheres are those values this destination is typically associated with and these values simply fit right in with the idea of leisure. The word 'dearest' is felt to resonate better with these values. Quite the contrary, if 'terhormat' was translated literally into 'respectable' or 'honorable,' the impression would have been very formal, strict, cold, stiff and unnatural. Word choices of 'respectable' or 'honorable,' in this context situation tend to create a clear boundary within the communication or the interaction process, which can make the visitors feel unwelcome. 'Dearest' still shows the degree of formality without sacrificing the warmth and welcoming nuances. The way SL views or positions the visitors is slightly shifted from the formal nuance into the neutral nuance yet still maintains the sense of respect or dignity in the TL.

4.1.3 SL: Kami Mohon Dukungan Anda...

TL: We Need Your Support...

The word 'mohon' has its literal translations, which are 'to ask' or 'to request' among many other options. Interestingly, the translator opts for 'need' in translating this word. The word 'need' in this context creates an invitation for visitors to take action together. On the other hand, word choices of 'to ask' or 'to request' tend to create some kind of enforcement. The word choices of 'to ask' or 'to request' tend to create an impression that a certain instruction or rule must be obeyed strictly. There is a sense of authoritarianism conveyed by these two words. Circling back to the idea of warmth, togetherness, friendliness and informal atmospheres, these two words of 'to ask' and 'to request' might share less with these values. The translation in fact communicates the messages without sending out the idea of some tension, intimidation or enforcement. The word 'need' on the other hand, conveys a message that the management of The Sacred Monkey Forest Sanctuary Ubud engages the visitors to work together in creating this place as a nonsmoking area. This place explicitly states that they are in need of support from the visitors instead of enforcing them to do the required or expected action of not smoking. The word choice of 'need' can be realized creating a sense of solidarity that does not only involve the management of this place but the participation from the visitors as well in achieving the goal or the targeted action. This translation is very clever at warning the visitors in a less intimidating manner. This translation clearly shows that there is a change in the point of view on how the management of this place expresses their demand or expectations toward the visitors.

\subsubsection{SL: Terima Kasih Atas Kerja Samanya}

TL: Thank You for Your Cooperation.

The above translation also proves that the translation for this first public sign is natural. The suffix in bold-nya is not translated literally by using the article 'the' or the possessive pronounce 'its' right before the word 'cooperation' in the TL. The translator in fact utilizes the word 'your' to transfer the meaning -nya. If the TL were 'Thank you for the or its cooperation' then it would have sounded unnatural. Another interesting word choice observed from the SL is the fact that the writer seems to create a less direct impression by selecting the suffix -nya. The possible alternative word choice to be put right there is 'Anda,' which makes the sentence read 'Terima kasih atas kerja sama Anda.' This word of 'Anda' is substituted by the suffix - nya. The suffix - nya is chosen probably with the intention to blend in the addressed audiences of varied ages. For example, 'Anda' sounds very formal for maybe an eleven-year-old visitor. Even though this word ' $A n d a$ ' is not selected or explicitly stated in the SL, the translator seems to be capable of communicating this concealed notion by using 'your' as the translation. In addition, the word 'your' in the TL indicates a sense of participation from visitors in making sure that this action goes well. There is a change in terms of how the object is viewed differently in the SL and the TL. The object is stated explicitly in the TL meanwhile it seems to be purposely stated 'vaguely' or less direct in the SL.

These three analyses for Data 4.1.2, 4.1.3 and 4.1.4 show that the translator applies Modulation as the translation procedure in translating this first public sign. The distinctive feature observed from these three analyses is the fact that there is a change in the point of view in each of the translations. Data 4.1.2 shows that there is a change or different ways of positioning the visitors in the SL and the TL. Moreover, a change in the point of view is also observed on Data 4.1.3 in reflecting the sense of demand expressed by the SL and the TL. Meanwhile, the way the object is perceived on Data 4.1.4 is also different. The SL states the object in a less direct way, while the TL explicitly states the object. The way the readers view the object is therefore clearly shifting. The idea of a change in the point of view goes in line with the core concept of this translation procedure, which can be observed from this explanation as follow.

Modulation is a variation of the form of the message, obtained by a change in the point of view. This change can be justified when, although a literal, or even transposed, translation results in a grammatically correct utterance, it is considered unsuitable, unidiomatic or awkward in the TL. (Vinay \& Darbelnet, 2000, p.89). 
The above quotation perfectly addresses the issues observed in these last three analyses. If there were no changes in the point of view, these three translations could still have been grammatically correct; however, the translation would have been unsuitable or awkward. Addressing young visitors with greetings of the 'honorable' or the 'respectable' shown on Data 4.1.2 clearly sounds 'way too much' and very unnatural. By applying this Modulation, the translator does not only transfer the message well but also assures the target audiences will feel comfortable accepting the process of transferring the meaning in the SL into the TL without sacrificing the context and sense of understanding of the TL audiences' cultural background. The choice of using 'Dearest' in fact can articulate a sense of welcome to every visitor of all ages without creating an awkwardness or state of cringing.

The second public sign is found at the entrance of Petulu Village, which is famously known for its main attraction of Kokokan, Heron Bird Colony Watch. This public sign consists of two clauses and there is a grammatical error identified in its second English clause translation.

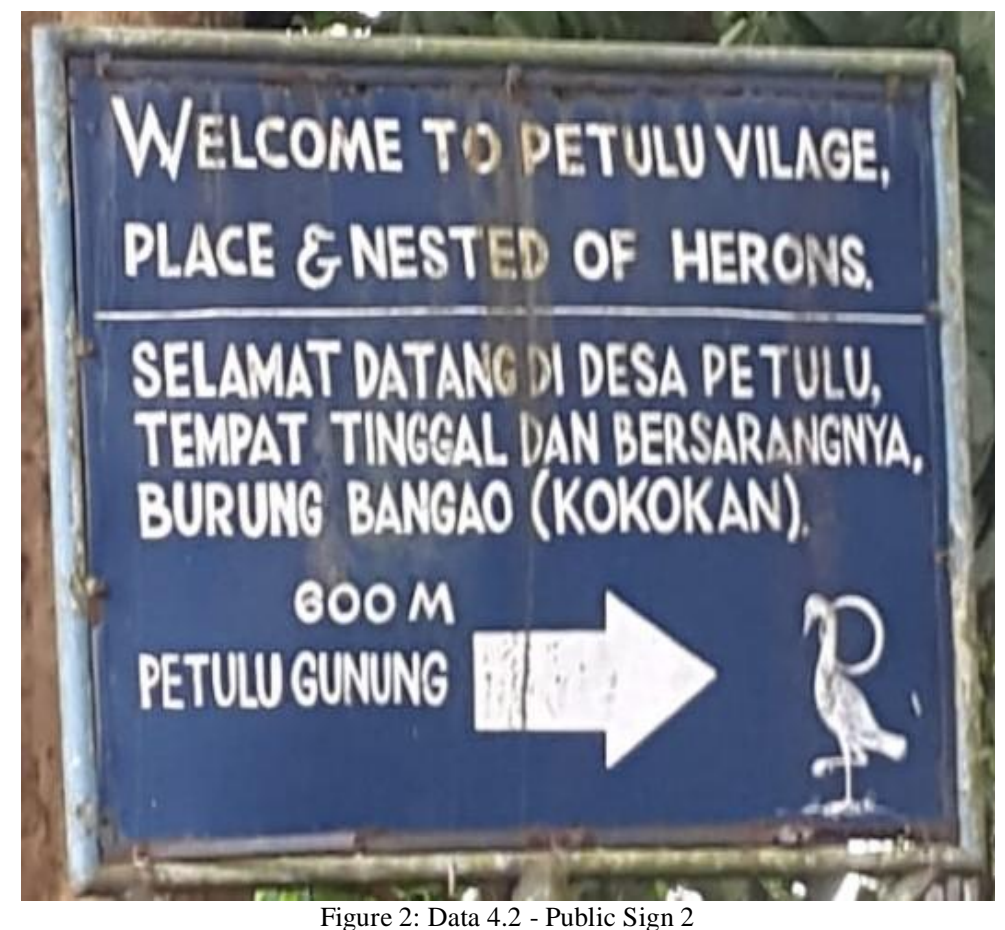

\subsubsection{SL: Selamat Datang Di Desa Petulu}

TL: Welcome to Petulu village,

The translation of the first clause above does not have any grammatical errors. The translator seems to apply Transposition as the translation procedure in transferring the meaning from the SL into the TL. The clue can be identified from the way the translator translates the last two words, which are 'desa Petulu.' Instead of opting for the Direct Translation method, the translator seems to make a change in the grammatical category. If the translator opts for the Direct Translation, the alternative translation would have been 'Welcome to the village of Petulu.' However, the translator does not follow the structure or the form of the SL, the translator switches the position of 'desa' and 'Petulu.' The noun phrase 'desa Petulu' is translated into 'Petulu village.' The core noun in this phrase is 'village,' while the modifier is the word 'Petulu.' This translation shows that there is a change in the grammatical category without altering the meaning of the text. Vinay \& Darbelnet in Venuti (2000) highlights this principle of Transposition procedure as follow.

The method called transposition involves replacing one word class with another without changing the meaning of the message... From a stylistic point of view, the base and the transposed expressions do not necessarily have the same value. Translators must, therefore, choose to carry out a transposition if the translation thus obtained fits better into the utterance. (p. 88).

The second English clause translation appears to have an error, which can be identified by the word 'nested.' The SL active word of 'bersarangnya' is translated into a passive voice - 'nested.' In fact, the translator seems to miss an important component that can actually serve as a clue showing that the translator should not have opted for passive voice in translating this. The important component referred here is the suffix -nya at the end of the word 'bersarang.' The word 'bersarang' means 'to nest' in English. Suffix -nya has a strong connection with the preceding word of 'tempat' or 'place' at the beginning of this second clause. The phrase 'tempat tinggal' means 'a place to stay' in English. Suffix $-n y a$ at the end of the word 'bersarang' is the substitution for the word 'tempat.' The original form of 'bersarangnya' is actually 'tempat bersarang,' therefore; there should have been the word 'tempat' before the word 
'bersarang.' The complete sentence without the suffix -nya is 'tempat tinggal dan tempat bersarang burung Bangau (Kokokan).'

4.2.2 SL: Tempat Tinggal Dan Bersarangnya Burung Bangau (Kokokan)

TL: Place \& Nested of Herons.

When we look at data 4.2.2 above, specifically the SL, the second word of 'tempat' before the word 'bersarang' is substituted with the suffix -nya. The logical reason behind this decision might be as an attempt to avoid the redundancy in repeating the word 'tempat' twice in one clause. Therefore, the word 'bersarangnya' should not be translated by the passive voice since the information conveyed by the word 'bersarangnya' is the 'place to nest' or the 'place of nesting' Translating 'bersarangnya' into a passive voice of 'nested' can then be realized as a not so appropriately correct way of translating it. The alternative English translation for the second clause can in fact be one of these.

Alternative 1 : where Herons stay and nest.

Alternative 2 : a place of staying and nesting for Herons.

Alternative 3 : a place for Herons to stay and nest.

These three alternative translations can be said to be grammatically correct by utilizing the active voice and being able to re-express the original meaning in the SL into the TL. One of the factors, which might cause the grammatical error in the TL is the fact that the translator tends to transfer the meaning in the second clause by applying the procedure of Literal Translation. The common problems caused by the application of this procedure is making the translation structurally inappropriate, having no a corresponding expression within the metalinguistic experience of the TL or having a corresponding expression, but not within the same register. Data 4.2.2 can be a real example proving on how the application of a certain translation procedure can affect the grammatical correctness of the translation product. A change of grammatical category like the one opted for by the translator in translating the first clause or data 4.2.1 might be an appropriate solution in making sure the translation can be read and accepted, and having an appropriate accuracy, which can be identified from its grammar.

Another interesting notion can be observed from the third public sign, which is found in front of the local art shop in Ubud. The interesting part from this sign is on the phrase of 'Morning Price.'

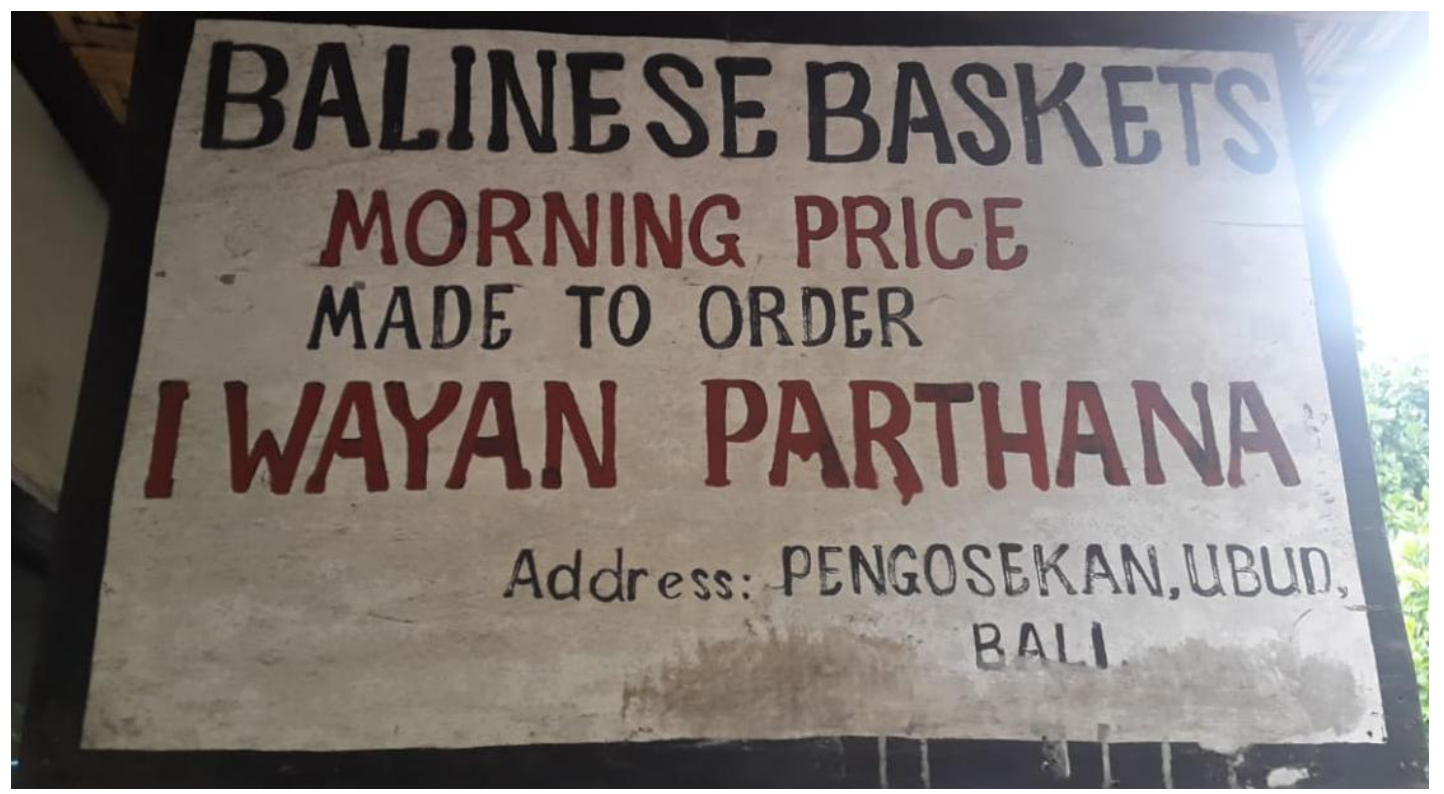

Figure 3: Data 4.3 - Public Sign 3

Grammatically speaking, there is nothing wrong with this phrase specifically or the entire phrase constructions on this sign in general, however the question raised is whether the English speakers are able to understand the message being conveyed by this phrase 'Morning Price.' This phrase can be translated into Indonesian as 'Harga Pagi.' Local sellers believe that successfully making a first sale in the morning can bring good luck for the rest of the sales in a whole day. Therefore, it is really important to make a sale in the morning, even though the profit generated might not be much. Local sellers in general do not mind selling their products very cheaply in the morning to make sure that the prospective buyers are willing to make a purchase in the morning. There is a popular belief among the local sellers that if the first sale is not made until midday, there will be no sales for that particular day since it symbolizes a sign of bad luck. The 'Morning Price' is commonly associated with being easy to bargain, a good deal or cheap price. The translation process for this sign is not only all about translating linguistic features but also transferring the cultural information from the SL into the TL. No wonder English speakers may find this phrase of 'Morning Price' unfamiliar since they may not share the same belief system or values as the local sellers do with the analogy of morning and price.

It can be realized that the translation of this phrase 'Morning Price' from the SL version of 'Harga Pagi' is unnatural. It can be read but hardly be understood and accepted by the TL audiences, who are English speakers. The translator 
appears to apply Transposition as the translation procedure in translating this phrase. There is a change in the grammatical category. The change can be noticed in how the translator switches the position of the core noun and the modifier from the one stated by the SL. Even though the equivalence for each of the words is found in English, the meaning does not really transfer adequately. This inadequacy impacts the level of acceptability as well as the level of accuracy on how this message needs to be perceived. This inadequacy also is shown to be the factor causing the unnaturalness of this translation. The alternative translation procedure, which can be proposed here is the procedure of Adaptation. The nature of this type of translation procedure seems to go in line with the issue encountered by this public sign, which is the cultural meaning transfer. Vinay \& Darbelnet (2000) explain the nature of the translation procedure of Adaptation as follow.

With this seventh method we reach the extreme limit of translation: it is used in those cases where the type of situation being referred to by the SL message is unknown in the TL culture. In such cases translators have to create a new situation that can be considered as being equivalent. Adaptation can, therefore, be described as a special kind of equivalence, a situational equivalence (p. 90-91).

Opting for another way in transferring the idea of good luck by making the first sale in the morning is what the translator may want to do to provide a natural and better translation. Therefore, the closest adaptation for 'Harga Pagi' may appear to be the 'Early Bird Sale.' Western culture believes that birds are the very first creatures who notice the sunrise; therefore, they are believed to be the very first creatures to wake up very early in the morning as well. There is even a proverb in English saying, 'The early bird gets the worm.' This proverb indicates that one who arrives or shows up first has the best chance for success. The notion of success here obviously can be associated with the idea of luck in making sales in the business world. 'Early Bird' therefore plays an important role in guiding the TL audiences in accepting the intended message being communicated by this third public sign. 'Early Bird' resonates quite similar sentiment or values with the idea of 'Harga Pagi' in Indonesian language. The phrase 'Morning Price' should have been translated as 'Early Bird Discount' or 'Early Bird Sale' in order to attract and inform the prospective buyers that the sellers are giving a super special discount for them if they are making a purchase early in the morning. Therefore, Adaptation is clearly the appropriate translation procedure, which needs to be applied in translating this public sign, specifically the 'Morning Price' part.

The fourth public sign also offers another unique experience in understanding the art and challenges of conducting the translation process. This public sign is informing visitors to Ubud about a man called Ketut Liyer, who is known as a Balinese traditional healer. He is also known to inherit the skills of traditional medicine and palm reading. The unique part about this public sign is the phrase 'Medicine Man.'

'Medicine Man' can be understood but this phrase does not feel natural for English speakers. The phrase 'Medicine Man' is not a commonly used phrase. Some English speakers may think this is an ancient or poetic way to refer to a doctor without further explanation in regard to their specialization or expertise in the medical world. The phrase 'Medicine Man' was long ago associated with the tradition from Native American history or culture. Therefore utilizing this 'Medicine Man' can be very confusing to some as this phrase connects with varied understandings and perceptions. The assumption, which can be drawn here, is the translator may want to translate the Indonesian version of 'Tukang Obat.' The word 'tukang' is translated into 'man,' meanwhile the word 'obat' is translated into 'medicine' in English. The word 'Tukang Obat' indicates that a person is selling different types of medicine. This person might be believed to have a good knowledge to sell as well as to recommend which types of medicine are suitable for patients with particular health problems. The translator seems to utilize Transposition as the translation procedure in translating this phrase. A change in the grammatical category is conducted in making sure the closest meaning expressed in the TL. The position of core noun of 'tukang' (man) is switched to the back being preceded by the word 'obat' (medicine). In spite of this effort, the translation produced still evokes a sense of unnaturalness. The other option, which can be adopted to cope with this issue, is to find another phrase or expression, which possesses the closest equivalence to the profession of Ketut Liyer. 


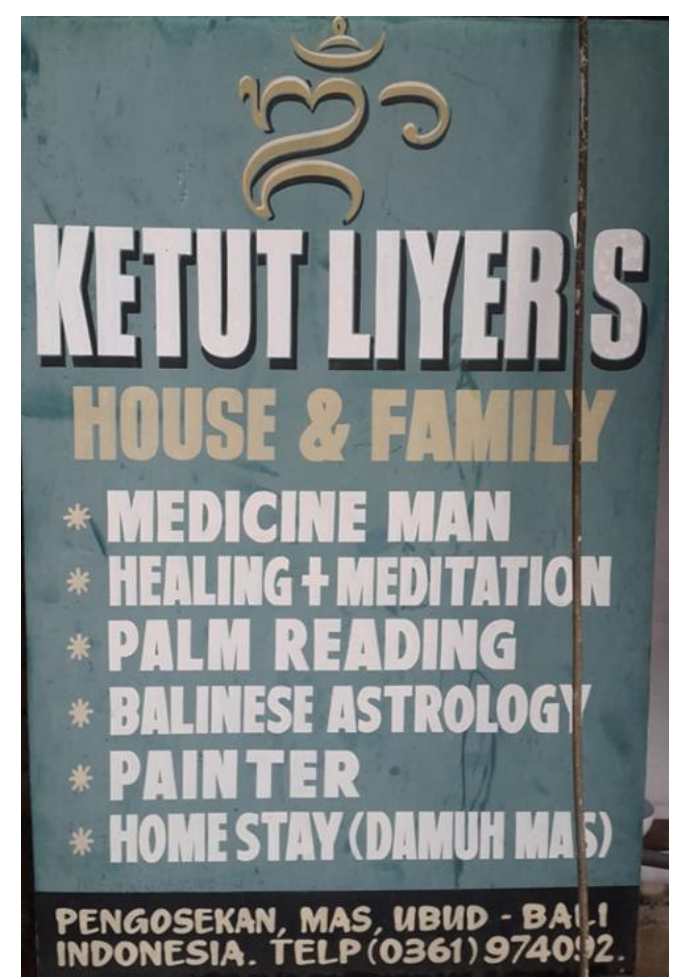

Figure 4: Data 4.4 - Public Sign 4

Instead of using the phrase of 'Medicine Man,' the translator can opt for other phrases in English; for instance, 'Shaman' and 'Traditional Healer.' These two can be regarded as the more appropriate options. Applying the concept of Modulation for translating this phrase can be done by changing the point of view in viewing the nature of this profession. The concept of 'Shaman' and 'Traditional Healer' might have differences compared to the 'Medicine Man.' The point of view about the 'Medicine Man' might be limited to the state of a figure selling, distributing or recommending medicines to other people. Meanwhile, the view people have when it comes to the 'Shaman' is a figure or a practitioner who conducts religious practices as well as interacting with a spirit world in order to redirect spiritual energies for healing purposes or some other purposes about spiritual and physical well-being. On the other hand, the phrase of 'Traditional Healer' is commonly viewed as a practitioner whose expertise is in traditional healing methods utilizing natural herbs and spices, holistic therapies and ancient wisdom to cure physical and mental illness. These two phrases of 'Shaman' and 'Traditional Healer' sound more natural compared to the phrase of 'Medicine Man' as well as articulating the intended meaning of what type of services or experiences Ketut Liyer offers to his clients. Changing the way how we picture or view a particular thing in one language to further re-express it in another language serves as the main nature of the Modulation procedure. This fourth public sign shows that a change in point of view provides an opportunity for the translators to accurately render the same situation or phenomenon in a different way, yet the meaning is still managed adequately well.

This fifth public sign shows another example on how strong the SL (Indonesian) linguistic feature influences the translation process. Therefore, awkwardness is inevitable in understanding the intended message of this public sign.

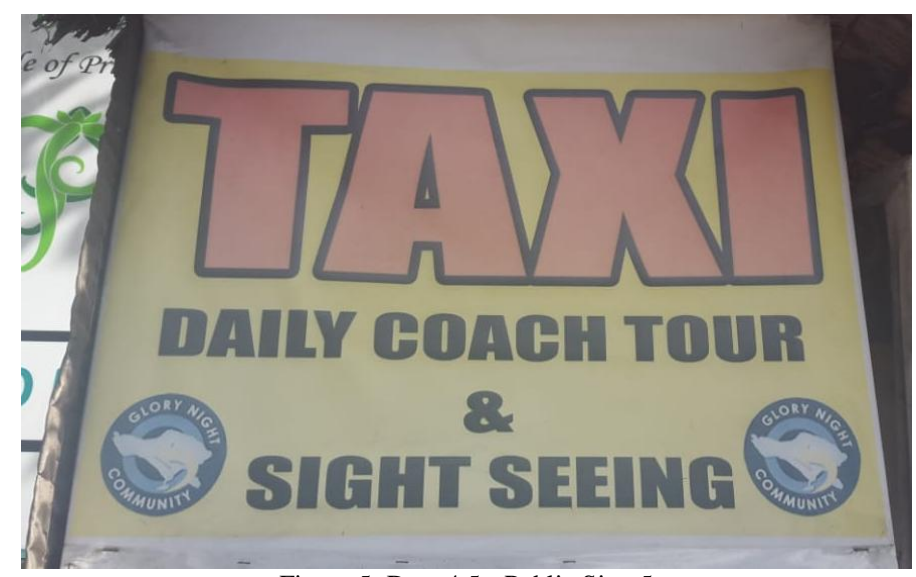

Figure 5: Data 4.5 - Public Sign 5 
This above public sign is found in front of one of the tourist information offices in Ubud. This company offers varied services, namely transportation, reservation for accommodation as well as leisure activities. One of the services captured from this public sign is read 'Daily Coach Tour.' At a first glance, this phrase may cause a confusion to some. The word 'coach' creates an unnatural nuance. The translator may intend to inform that this company offers a daily tour with a tour guide included in the package. Instead of using this phrase of 'Daily Coach Tour,' the translator could indeed opt for this alternative - 'Daily Guided Tour.' The unnatural nuance addressed previously exists because these two words (guided and coach) possess a slightly different notion in this context. When it comes to tour activity, the word 'guide' is a person who literally guides the entire activity, being known as a tour guide. No one will likely address the person in charge of this job as a 'coach.' In addition, the word 'coach' has a strong association with the idea of teaching or training other people in a particular skill. This entire context situation obviously does not require a sense of mentorship, which is often associated with the word 'coach.' Most tourists reserve this service to enjoy the leisure activity without expecting any forms of coaching. They simply require an itinerary along with a tour guide, who will assist the entire tour experience. Therefore, this English translation can be regarded as an unnatural one.

The translator, moreover seems to apply the procedure of Calque in translating this phrase 'Daily Coach Tour.' Below is provided two possible SLs, from which the TL may have been translated into.

4.5.1 (The Possible) SL 1: Tur Harian Berpemandu

(The Possible) SL 2: Tur Harian Dengan Pemandu

TL: $\quad$ Daily Coach Tour

The principal of this type of Calque procedure as a special kind of borrowing whereby a language borrows an expression form of another, but then translates literally each of its elements (Vinay \& Darbelnet, 2000). The translator obviously translates each word, however the position for these three words is adjusted to the English syntactical construction. The core noun is the word 'Tour' which locates at the very end, meanwhile the modifiers for this phrase, 'Daily Coach', appear preceding the core noun. If the translator did not literally translate each word in the SL, the TL would have simply been 'Daily Tour' without another modifier of 'coach' in between. The translator may think it is a necessary to insert an additional piece of information that the tour package does include a person, who will be in charge of the tour activity. This characteristic of translating each word from the SL into the TL with an adjustment in its syntactical construction appears to be one logical reason in identifying the application of Calque for this data. The application of this procedure can then be regarded as one of the factors contributing to the grammatical errors in this public sign. There are at least two grammatical errors identified.

The word 'coach' between the word 'daily' and the word 'tour' reflects the grammatical errors as this word should have been in the form of past participle. This past participle form will then indicate that there is a piece of information included within the entire phrase, in this case the tour guide is included within the service. Moreover, another obvious grammatical error is in the phrase 'Sight Seeing.' This should have been written as one single word 'Sightseeing' instead of being broken down into two words. The entire message that the translator may want to express through this public sign is the fact that this company offers a taxi service as well as an activity or a tour to do the sightseeing with a tour guide provided.

These five public signs show how intricate the translation process can be. There are a number of crucial aspects, which involve in the process of re-expressing the intended meaning from the SL into the TL. Linguistic and cultural aspects can be realized as two of the most crucial aspects contributing the quality of the translation product. Linguistic aspect assists the translator to communicate the messages from two different languages; meanwhile the cultural aspect regulates the way this information is being articulated. Analyzing these five public signs also provides an opportunity to really understand the beauty of language and culture and how they connect to each other to enrich the insights or the understanding human beings have about people and life. This research also discovers specific findings concerning the occurrence of the linguistic errors as well as the translation procedures applied in translating these five public signs. Below are the summary of these two findings, which also answer the two formulated problems of this research. Among these five selected public signs, it is found that the occurrence of the grammatical errors is identified in the first, second and the fifth public signs.

TABLE 1

The OCCurRence Of The Grammatical ERrors On These Five Public SiGNS

\begin{tabular}{|c|c|c|}
\hline No & Data & The Occurrence of the Grammatical Errors \\
\hline 1 & Public Sign 1 & Found \\
\hline 2 & Public Sign 2 & Found \\
\hline 3 & Public Sign 3 & Nound Found \\
\hline 4 & Public Sign 4 & Found \\
\hline 5 & Public Sign 5 & \\
\hline
\end{tabular}

As the second finding of this research, it is found that among seven translation procedures proposed by Vinay \& Darbelnet (2000), four procedures are identified being applied in translating these five public signs. 
TABLE 2

THE APPLiCATION OF THE TRANSLATION PROCEDURES

\begin{tabular}{|c|c|c|}
\hline No & Data & Translation Procedures \\
\hline 1 & Public Sign 1 & $\begin{array}{c}\text { Transposition } \\
\text { Modulation }\end{array}$ \\
\hline 2 & Public Sign 2 & $\begin{array}{c}\text { Transposition } \\
\text { Literal Translation }\end{array}$ \\
\hline 3 & Public Sign 3 & Transposition \\
\hline 4 & Public Sign 4 & Transposition \\
\hline 5 & Public Sign 5 & Calque \\
\hline
\end{tabular}

\section{CONCLUSIONS}

In compliance with the two formulated problems of this research, a number of findings can be concluded. As the first conclusion of this research concerning the occurrence of the grammatical errors, it is found that the first, second and the fifth public signs do have grammatical errors in the translation process. As the second conclusion of this research concerning the translation procedures applied in translating these five public signs, it is found among seven translation procedures being referred to, only four procedures are identified as being applied. Those four procedures are Modulation, Transposition, Literal Translation and Calque. Another interesting finding, which can be discovered in this research, is the fact that the application of the translation procedures for a certain context situation may contribute towards the quality of the translation products. The translator's decision in applying the appropriate translation procedures and the translator's good understanding in both linguistic and cultural aspects certainly determine the level of readability, acceptability as well as the level of accuracy of the translation products. Likewise, the inappropriate application of the translation procedures may appear to be the contributing factors in causing the grammatical errors in the translation process.

\section{REFERENCES}

[1] Aristova, N. (2016). English Translations in the Urban Linguistic Landscape as a Marker of an Emerging Global City: The Case of Kazan, Russia. Procedia: Social and Behavioral Sciences, 231, 216-222.

[2] Beili, Z \& Xu, Tuo. (2015). English Translation of Linguistic Signs: A Study from the Perspective of Linguistic Landscape. CSCanada, 11(3), 35-42.

[3] Bungin, B. (2007). Penelitian Kualitatif: Komunikasi, Ekonomi, Kebijakan Publik, dan Ilmu Sosial Lainnya. Kencana.

[4] Halliday, M.A.K. \& Matthiessen, C, M.I.M. (2014). Halliday's Introduction to Functional Grammar. Routledge.

[5] Jiang, W. (2000). The Relationship between Culture and Language. ELT Journal. 54(4), 328-334.

[6] Koskinen, K. (2012). Linguistic Landscape as a Translational Space: the Case of Hervanta, Tampere. Helsinki Collegium for Advanced Studies, 13, 73-92.

[7] Larson, M., L. (1998). Meaning - Based Translation: A Guide to Cross - Language Equivalence. University Press of America, Inc.

[8] Sudaryanto. (1993). Metode dan Aneka Teknik Analisis Data (Pengantar Penelitian Wahana Kebudayaan secara Linguis). Duta Wacana University Press.

[9] Vinay, J. P. \& Darbelnet, J. (2000). A Methodology for Translation. In Venuti, Lawrence (Eds.), The Translation Studies Reader (pp. 84-93). Routledge.

Ni Made Ariani received her bachelor's degree in English Literature from Sekolah Tinggi Bahasa Asing (STIBA) Saraswati Denpasar, Bali, Indonesia in 2013 and her master's degree in Applied Linguistics - Translation Studies from Udayana University, Bali, Indonesia in 2016. She is currently a Ph.D student of linguistic study program at Udayana University, Bali, Indonesia. She received the Fulbright Foreign Language Teaching Assistant (Fulbright FLTA) scholarship in Asian Languages and Cultures Department at University of Michigan, United States of America in 2018 - 2019. Her research interests include translation studies, semiotics, cultural studies and Indonesian Language for Foreign Speakers (BIPA).

Ketut Artawa is a professor of linguistics at Udayana University, Bali, Indonesia. He obtained his MA in Linguistics in 1992 and Ph.D in Linguistics in 1995 from La Trobe University, Melbourne. He was a visiting Professor at the Research School of Pacific Studies, the Australian National University (October 2009 - January 2010) and a Visiting Professor at the Research Institute for Languages and Cultures of Asia and Africa (ILCAA / AA-ken), Tokyo University of Foreign Studies (TUFS), Japan (2011 - 2012). His research interests are in the fields of syntax, semantics, language typology, and linguistic landscape. 